\title{
A Rare Cause of Meningitis: Lactobacillus Casei
}

\author{
(D) Abdullah Yazar ${ }^{1}$, (1) Fatih Akın 1, () Esra Türe1, (1) Metin Doğan² \\ ${ }^{1}$ Departments of Pediatrics and Pediatric Emergency, Necmettin Erbakan University Meram Faculty of Medicine, Konya, Turkey \\ ${ }^{2}$ Department of Microbiology, Necmettin Erbakan University Meram Faculty of Medicine, Konya, Turkey
}

\begin{abstract}
Lactobacillus casei is a probiotic bacteria found in the human mouth and intestine. These microorganisms, which are known to be effective in controlling oral infections and in the prevention and treatment of gastrointestinal diseases, rarely cause infection in healthy people. Here, Lactobacillus casei was observed in the cerebrospinal fluid culture of a child who was hospitalized in the intensive care unit. In cases with gastrostomy and recurrent meningitis, Lactobacillus casei should be considered as a pathogenic cause.

Keywords: Child; Lactobacillus casei; meningitis.
\end{abstract}

$\mathrm{R}_{\mathrm{s}}$ ecurrent meningitis is defined as 2 or more episodes of meningitis in which the clinical and laboratory findings of the patient are fully normalized in the intervening period ${ }^{[1]}$. It is a rarely seen condition and underlying predisposing factors should be investigated. The most frequently seen predisposing etiologies include immune system disorders, congenital cranial defects, a ventriculoperitoneal (VP) shunt, or as the result of direct communication of the subarachnoid space with the skin or mucosa following head trauma ${ }^{[2]}$.

In most cases of bacterial meningitis, a pathogen can be isolated; however, in some cases no pathogen can be detected ${ }^{[2,3]}$. In recent years, multidrug-resistant microorganisms have emerged at the forefront in cases of recurrent meningitis ${ }^{[4]}$. Lactobacillus spp. are found among the oral and intestinal flora, and rarely cause infection ${ }^{[5]}$. L. casei is a Gram-positive, immobile, facultative anaerobe that does not form spores. This microorganism may be isolated from soil, as well as the gastrointestinal system and breast milk.
These bacteria generally have a favorable effect on health by inhibiting the growth of pathogenic microorganisms ${ }^{[6]}$. In this case of a patient with cerebral palsy and a history of a gastrostomy and recurrent meningitis, Lactobacillus casei was a rarely seen agent of meningitis.

\section{Case Report}

An 8-year-old male patient with a VP shunt and a diagnosis of cerebral palsy and hydrocephalus was presented at the emergency polyclinic of the department of children's health and diseases with the complaints of fever, vomiting, and impaired general health. His personal history was unremarkable, other than a traffic accident 8 months earlier. His family history was also unremarkable. Following the accident, he developed neuromotor sequelae, and VP shunt surgery was performed due to hydrocephalus. Three episodes of meningitis related to the VP shunt occurred. The shunt had been removed 1 month prior to presentation. Growth of Acinetobacter baumanii had been detected in

Correspondence (iletişim): Abdullah Yazar, MD. Department of Pediatrics and Pediatric Emergency, Necmettin Erbakan University, Meram Faculty of Medicine, Konya, Turkey

Phone (Telefon): +90 5065036841 E-mail (E-posta): drabdullahyazar@hotmail.com

Submitted Date (Başvuru Tarihi): 09.10.2017 Accepted Date(Kabul Tarihi): 22.12.2017

Copyright 2018 Haydarpaşa Numune Medical Journal

This is an open access article under the CC BY-NC license (http://creativecommons.org/licenses/by-nc/4.0/). 
the cerebrospinal fluid (CSF) during the last attack. After 14 days of treatment with ceftazidime, he had been discharged. Physical examination revealed a body temperature of $38.3^{\circ} \mathrm{C}$, a peak heart rate of $118 /$ minute, a respiratory rate of $28 /$ minute, and a blood pressure of $105 / 60 \mathrm{~mm}$. He was unconscious and did not respond to painful stimuli. Marked neck stiffness was observed. The pupils were isochoric, but light reflex was not present. Bilateral crepitant rales were detected on examination of the respiratory system. His gastrostomy was functional. Examination results of other organ systems were within normal limits.

The laboratory test results were a white blood cell (WBC) count of $14300 / \mathrm{mm}^{3}$, a hemoglobin count of $13.3 \mathrm{~g} / \mathrm{dL}$, a platelet count of $675000 / \mathrm{mm}^{3}$, an erythrocyte sedimentation rate of $57 \mathrm{~mm} /$ hour, and a C-reactive protein level of $171.5 \mathrm{mg} / \mathrm{dL}$. A peripheral blood smear indicated $65 \%$ segmented forms, $25 \%$ rods, $18 \%$ lymphocytes, $14 \%$ monocytes, and $0.1 \%$ eosinophils. Chest radiograms revealed infiltrative areas, and he was hospitalized in the intensive care unit with an initial diagnosis of meningitis and pneumonia. The department of neurosurgery was consulted, and an external shunt was implanted. CSF samples obtained during procedure contained $3201 \mathrm{mg} / \mathrm{dL}$ protein and $161 \mathrm{mg} / \mathrm{dL}$ glucose, and his fasting blood sugar was 197 $\mathrm{mg} / \mathrm{dL}$. Microscopic examination of the CSF fluid sample yielded a WBC of $14300 / \mathrm{mm}^{3}$. A culture of the CSF sample was obtained and routine doses of vancomycin and cefotaxime to treat meningitis were initiated. The patient's general health deteriorated, and manifestations of shock developed in the follow-up period. Loading doses of physiologic saline were infused twice, and administration of dopamine was implemented as inotropic support. An infusion of midazolam was initiated on the second day of hospitalization due to the development of treatment-resistant convulsions. Cerebral magnetic resonance imaging was consistent with hydrocephalus, ventriculitis, and meningitis. CSF material was incubated on automated blood culture media (BacT Alert; BioMérieux, Marcy l'Etoile, France) and blood agar culture media, and growth of Lactobacillus casei was detected. Identification of the bacteria was performed using conventional methods and matrix assisted laser desorption ionization time-of-flight technology (Vitek MS system; BioMérieux, Marcy l'Etoile, France). Treatment was continued based on these results. On the fifth day of hospitalization, his fever resolved and his blood pressure dropped to a normal level. Inotropic support was discontinued. Since his convulsions were under control, the midazolam infusion was tapered and eventually eliminated. No bacterial growth was detected on control CSF culture media. Antibiotherapy was maintained for 14 days and he was discharged healthy.

\section{Discussion}

Central nervous system defects, skull base fractures, parameningeal infections, and immune deficiencies are known to be the most frequent predisposing causes of recurrent purulent meningitis ${ }^{[7]}$. In this report, a case of Lactobacillus casei meningitis in a patient who had undergone VP shunt implantation due to the development of hydrocephalus after head trauma was described.

Streptococcus pneumoniae is the causative agent in most posttraumatic infections; however, in recent years, an increase in the number of cases of meningitis secondary to Gram-negative agents has been observed and attributed to the colonization of nasopharyngeal flora by multidrug-resistant microorganisms $[8,9]$. Findings of multidrug-resistant bacteria have been reported in this group of patients [4]. Our patient experienced 3 episodes of meningitis, the last 1 month prior to this hospitalization. In the last CSF culture, Acinetobacter spp. that was susceptible to third-generation cephalosporins was detected, and the patient received antibiotherapy for 14 days.

The Lactobacillus family is a complex group, consisting of more than 170 phenotypically similar bacterial species [10]. L. casei and L. rhamnosus are the most frequently seen. Though this microorganism can lead to infection in many organ systems, endocarditis and bacteremia are reported most often. Rarely, Lactobacillus has also been isolated in cases of peritonitis, abscess, and meningitis ${ }^{[11]}$. In cases of recurrent episodes of meningitis, especially following head trauma, Lactobacillus spp. should not be overlooked among potential causative microorganisms. Schmidt et al. ${ }^{[12]}$ reported isolation of Lactobacillus rhamnosus in a patient who developed meningitis secondary to fistula occurring in the space between the esophagus and the subarachnoidal space as a complication of cervical vertebral surgery. In our case, the clinical and laboratory findings were consistent with bacterial meningitis. Growth of Lactobacillus casei was detected on routine CSF culture media. Although these culture media was appropriate for the growth of other resistant microorganisms, no other bacteria were isolated. Therefore, our patient was considered a case of Lactobacillus casei meningitis.

Lactobacillus casei is a probiotic microorganism found among the gastrointestinal flora; it rarely becomes pathogenic in healthy individuals ${ }^{[9]}$. In the presence of underlying factors, such as malignancy, long-term antibiotic use, diabetes mellitus, organ transplantation, or chronic 
disease, it can cause infection in the host ${ }^{[11]}$. There was no probiotics use in this case that would suggest the source of infection. However, our patient had many predisposing factors: head trauma, hydrocephalus, VP shunt, gastrostomy, history of recurrent episodes of meningitis, and long-term use of broad spectrum antibiotics, all of which suggested that his own gastrointestinal flora were the source of the central nervous system infection.

Lactobacillus spp. can occasionally cause bacteremia in individuals with an intact immune system ${ }^{[13]}$. Robin et al. ${ }^{[14]}$ reported Lactobacillus rhamnosus meningitis following recurrent episodes of septicemia in a child who had undergone bone marrow transplantation with the indication of acute leukemia. Passera et al. ${ }^{[15]}$ reported 3 patients with Lactobacillus casei sepsis hospitalized in a pediatric intensive care unit. Our case was hospitalized in an intensive care unit with the initial diagnosis of meningitis and pneumonia, and septic shock developed during the follow-up period. However, no bacterial growth was detected in the blood cultures of our patient.

Lactobacillus spp. are Gram-positive, anaerobic bacteria that are known to usually be sensitive to erythromycin and clindamycin [11]. Resistance to metronidazole, ciprofloxacin, and aminoglycosides has been reported ${ }^{[10]}$. Empirical treatment with vancomycin and cefotaxime was initiated in the present case without waiting for the results of antibiotic susceptibility test results. In our laboratory, antibiograms to identify $L$. casei could not be performed; however, treatment led to clinical improvement and a control culture that revealed no growth.

In conclusion, in recent years, due to a decrease in the death rate in intensive care units and longer hospital stays, long periods of antibiotic use and the related development of resistance, as well as an increase in the number of gastrostomies performed, infectious microorganisms are now encountered more frequently. The measures to be taken and the development of prophylactic and therapeutic methods will require larger scale studies.

Informed Consent: Approval was obtained from the patients.

Peer-review: Externally peer-reviewed.

Conflict of Interest: None declared.

Authorship Contributions: Concept: A.Y., M.D.; Design: A.Y., F.A..; Data Collection or Processing: E.T., M.D.; Analysis or Interpretation: A.Y., E.T.; Literature Search: A.Y.; Writing: A.Y., F.A., E.T., M.D.

Financial Disclosure: The authors declared that this study received no financial support.

\section{References}

1. Yogev R. Recurrent Meningitis. In: Long SS, Plckering LK, Prober CG, editors. Principles and Practice of Pediatric Infectious Diseases. 2nd ed. New York: Churchill-Livingstone; 2003. p. 279-84.

2. Dalgıç N, İnce E, Çiftçi E, Öncel S, Fitoz S, Doğru Ü. Recurrent streptococcus pneumoniae meningitis and Mondini dysplasia: a case report. Turk Pediatri Ars 2004;39:44-7.

3. Tunkel AR, Hartman BJ, Kaplan SL, Kaufman BA, Roos KL, Scheld WM, et al. Practice guidelines for the management of bacterial meningitis. Clin Infect Dis 2004;39:1267-84. [CrossRef]

4. Kallel $H$, Chelly $H$, Ghorbel $M$, Bahloul M, Ksibi $H$, Rekik N, et al. Posttraumatic meningitis: incidence, bacteriology, and outcomes. Neurochirurgie 2006;52:397-406. [CrossRef]

5. Cannon JP, Lee TA, Bolanos JT, Danziger LH. Pathogenic relevance of Lactobacillus: a retrospective review of over 200 cases. Eur J Clin Microbiol Infect Dis 2005;24:31-40. [CrossRef]

6. Sömer VF, Akpınar D, Başyiğit Kılıç G. Lactobacillus casei'nin Sağlık Üzerine Etkileri ve Gıda Endüstrisinde Kullanımı. GIDA 2012;37:165-72.

7. Yalçın I, Güler N, Partalcı A, Öneş Ü, Salman N. Çocuklarda Tekrarlayan Bakteriyel Menenjit. Klimik Derg 1992;5:53-5.

8. Hand WL, Sanford JP. Posttraumatic bacterial meningitis. Ann Intern Med 1970;72:869-74. [CrossRef]

9. Buckwold FJ, Hand R, Hansebout RR. Hospital-acquired bacterial meningitis in neurosurgical patients. J Neurosurg 1977;46:494-500. [CrossRef]

10. Goldstein EJ, Tyrrell KL, Citron DM. Lactobacillus species: taxonomic complexity and controversial susceptibilities. Clin Infect Dis 2015;60 Suppl 2:S98-107. [CrossRef]

11. Cannon JP, Lee TA, Bolanos JT, Danziger LH. Pathogenic relevance of Lactobacillus: a retrospective review of over 200 cases. Eur J Clin Microbiol Infect Dis 2005;24:31-40. [CrossRef]

12. Schmidt M, Maxime V, Pareire F, Carlier R, Lawrence C, Clair B, et al. A lethal case of meningitis due to Lactobacillus rhamnosus as a late complication of anterior cervical spine surgery. J Infect 2011;62:309-10. [CrossRef]

13. Tommasi C, Equitani F, Masala M, Ballardini M, Favaro M, Meledandri $M$, et al. Diagnostic difficulties of Lactobacillus casei bacteraemia in immunocompetent patients: a case report. J Med Case Rep 2008;2:315. [CrossRef]

14. Robin F, Paillard C, Marchandin H, Demeocq F, Bonnet R, Hennequin $C$. Lactobacillus rhamnosus meningitis following recurrent episodes of bacteremia in a child undergoing allogeneic hematopoietic stem cell transplantation. J Clin Microbiol 2010;48:4317-9. [CrossRef]

15. Passera M, Pellicioli I, Corbellini S, Corno M, Vailati F, Bonanomi $\mathrm{E}$, et al. Lactobacillus casei subsp. rhamnosus septicaemia in three patients of the paediatric intensive care unit. J Hosp Infect 2016. pii: S0195-6701(16)30440-6. 